\title{
REVIEW OF FUNDAMENTAL NUCLEAR-GEOPHYSICAL RESEARCHES IN OSENU: I. STANDARD BETA DECAY THEORY ELEMENTS AND NEW COOPERATIVE ELECTRON- $\beta$-NUCLEAR SPECTROSCOPY
}

\author{
A.V. Glushkov , Dr. Sci. (Phys.-Math.) \\ Odessa State Environmental University, 15 , \\ LvivskaSt.,65016Odessa,Ukraine, glushkovav@gmail.com
}

\begin{abstract}
This paper opens a series of publications, devoted to review of new results of the original nucleargeophysical researches at the OSENU mathematics department and its laboratories (computational and quantum mathematics and mechanics, environmental radioactivity, nuclear geophysics). Primarily the first material will focus on fundamental issues that constitute the theoretical basis of the further applied nuclear geophysical research. It is shortly presented a modern approach to computing the key parameters of the beta decay processes. There are discussed the cooperative electron $\beta$-nuclear processes in atoms and molecules, including the excitation, ionization, electronic rearrangement, induced by the nuclear reactions and $\beta$-decay. A few factors are taken into account: changing the integration limits in the Fermi function integral, energy corrections for different chemical substances, and the possibility of the bound $\beta$-decay or other exotic decay channels.
\end{abstract}

Key words: nuclear geophysics, electron $\beta$-decay processes, cooperative electron-beta-nuclear spectroscopy

\section{INTRODUCTION}

This paper opens a series of publications, devoted to review of new results of the original nuclear-geophysical researches at the OSENU mathematics department and its laboratories (computational and quantum mathematics and mechanics, environmental radioactivity, nuclear geophysics). Primarily the first material will focus on fundamental issues that constitute the theoretical basis of the further applied nuclear-geophysical research [1-30].

Let us remind the classical definitions. As it is well known, a nuclear geophysics usually studies a spreading radioactive elements and stable isotopes in the Earth, the impact of this distribution on the geological history of the Earth and the issues of determining the absolute age of the Earth's crust as well as the processes leading to the concentration of radioactive elements in various areas of the LC and the formation of industrial fields [1-4]. Besides, there are considered the methods of investigation of the Earth's crust geological structure based on the radioactive radiation emission and studying the nuclear properties of elements. The direct tasks of nuclear geophysics are connected with studying spatial energetic and spatiotemporal distribution of eradiation in substance under known fundamental characteristics (such as cross-sections of elementary processes of interaction of radiation with substance etc). Surely, theoretical solving is based using the mathematical models of radiation spreading in different mediums. Artificial radioactivity occurs during irradiation of rocks and environments by gamma rays or neutrons. By measuring certain characteristics of the induced field, one can judge about the gamma and neutron properties of rocks, which are determined by the chemical composition of elements and physical properties of rocks. There are many man-made nuclear-physical methods for determining the chemical composition and physical properties of rocks based on the use of a neutron (neutron, neutron-gamma, etc.) or gamma radiation (gamma-gamma, gamma-neutron, X-ray radiometric etc). One should mention so-called geocosmic method based on the underground registration of space muons, which is related to modern nuclear geophysics too (see details in Ref.[1-4]). One of the most actual and important problem is connected with correct quantitative description of environmental radioactivity dynamics as well as standard geosphere's dynamics [31,32]. Usually one should note the following actual problems such as long-term investigation of the behavior of radionuclides in the environment, elucidation of the mechanism of transfer of radionuclides in the environment. It is of a great interest a radionuclide transport in geospheres, the terrestrial radionuclide dynamics - research radionuclide transfer and migration in the terrestrial environment etc. The main purposes of modeling, measurements and forecasting approach include to evaluate and predict environmental radionuclide transfer and radiation through using computer simulations and other methods, to develop improved technologies to monitor and measure radiation.

As it is noted above, we start from fundamental issues that constitute the theoretical basis of the further applied 
studies and discuss the cooperative electron $\beta$-nuclear processes in atoms and molecules, including the excitation, ionization, electronic rearrangement, induced by the nuclear reactions and $\beta$-decay. It is shortly presented a modern approach to computing the key parameters of the beta decay processes. A few factors are taken into account: changing the integration limits in the Fermi function integral, energy corrections for different chemical substances, and the possibility of the bound $\beta$-decay or other decay channels.

\section{REVIEIW OF MOST IMPORTANT RESULTS MOD- ERN PROBLEMS}

Methods for influencing the radioactive decay rate have been sought from the first years of formation of nuclear physics. Beta decay strengths influence nuclear transmutations, the pathways of stellar nucleosynthesis in stars and the resulting abundance of atomic nuclei. Nuclear transmutation (i.e. change in the nuclear charge) induced by nuclear reactions of radioactivity are often accompanied by a redistribution of the electrons around the final transmuted nucleus. Electrons originally in the ground state of the target atom (molecule) can be excited either in the bound spectrum or to the continuum of energy. Calculations of the population distribution of the atomic states of the daughter atom require a complete description of both the bound spectrum and the continuum of energy. Calculation of the $\beta$ decay parameters while taking into account the cooperative electronic processes (an interaction between beta particle, generated by an atomic nucleus, and the electron shells, which surround a beta active nucleus in the atomic or molecular system) and the chemical environment contribution is now of a great theoretical and experimental interest (see, for details, Refs. [5-18]). Discrepancies in the experimental data for parameters of the $\beta$-decay in the heavy radioactive nuclei can be partly explained by contributions of the cooperative electron-nuclear processes and chemical bond effect. Naturally, the problem of detecting a neutrino mass is of a great importance.

The possible source of the corresponding data about it is the $\beta$-decay spectrum shape. As it is well known, neutrinos were postulated by Pauli (1930) to properly explain the $\beta$-decay of the free neutron $\mathrm{n} \rightarrow \mathrm{p}+\mathrm{e}^{-}+\bar{v}_{\mathrm{e}}$ without violating energy-momentum conservation. In the last years new experimental feasibilities have allowed for improvements in the measurement of the $\beta$-decay parameters resulting in a more accurate definition of the neutrino mass $[5,6]$. These data are especially important for standardization of the beta decay parameters for a whole number of the heavy radioactive nuclei. It is interesting to note that discrepancies in data on the half-life period for ${ }^{241} \mathrm{Pu}$ are not explained hitherto, though quite a reasonable comment is connected with taking into account the bound $\beta$-decay channel etc (see Refs. [7]). The population distribution of the atomic states of the daughter atom requires a complete and correct description of the cooperative electron-nuclear processes and chemical environment effect on the $\beta$-decay parameters [5-18].

One has to consider the following effects [7]: i) Changing the electron wave functions because of the changing atomic electric field; changing the valence shell occupation numbers in different chemical substances; ii) The integration limits (calculating the Fermi integral function) are also changed in a case of the different chemical substances; as a rule, $\beta$-particle and neutrino take away the difference between the initial and transmuted final nuclei, provided by the nuclear and electronic rearrangement. One must also mention the additional channel, when $\beta$-electron occupies a free state in the bound atomic spectrum. Approaches implemented up to now can be characterized as force ones using, first of all, the change in energy balance of radioactive decay: creation of isomeric states, variation of energy of the chemical bond in molecules with radioactive atoms and $\beta$-decay to bound states in the ionized atoms.

The last channel was discovered for the first time in experiments on the synchrotron and SIS/ESR (GSI, Germany), when the bound $\beta$ decay ${ }^{163} \mathrm{Dy}^{66+} \rightarrow{ }^{163} \mathrm{Ho}^{66+}$ was studied by using the technology of the highly-or fullyionized atomic beams (multicharged ions) (see details in [7] and references therein). In fact, the $\beta$-transition $\mathrm{Dy}^{66+} \rightarrow \mathrm{Ho}^{66+}$ was observed, which is accompanied by a capture of the $\beta$-particle on the $K$ and $L$ shell levels in the bound spectrum of the daughter atom. In fact, the complete ionization of ${ }^{163}$ Dy in the storage ring of a heavy ion accelerator makes its beta decay to the $K$ shell of ${ }^{163} \mathrm{Ho}$ possible, with a half-life of 47 days, while in the neutral atom this decay is energetically forbidden. The similar effect was obtained for ${ }^{187} \mathrm{Re}$. Let us remember also that such an effect may be responsible for creation of elements in the space and astrophysical plasma (see details in Refs. [5,18-20]). The important results are linked with the first measurement of a ratio $\lambda_{\beta b} / \lambda_{\beta c}$ of bound-state $\left(\lambda_{\beta b}\right)$ and continuum-state $\left(\lambda_{\beta c}\right) \beta^{-}$-decay rates for the case of bare ${ }^{207} \mathrm{Tl}^{81+}$ ions. These ions were produced at the GSI fragment separator FRS by projectile fragmentation of a ${ }^{208} \mathrm{~Pb}$ beam. The half-lives of isomeric states of fully ionized ${ }^{144} \mathrm{~Tb},{ }^{149} \mathrm{Dy},{ }^{151} \mathrm{Er}$ were measured too (see [6-10] and references therein). These nuclides were produced via fragmentation of about $900 \mathrm{MeV} / \mathrm{u}{ }^{209} \mathrm{Bi}$ projectiles, separated in flight with the fragment separator (FRS) and stored in the cooler ring (ESR). The authors of Ref. [18] observed for the first time drastic increases of the halflives of bare isomers by factors of up to 30 compared to their neutral counterparts. This phenomenon is due to the exclusion of the strong internal conversion and electron- 
capture channels in the radioactive decay of these bare nuclei. The authors of Ref. [7] reported on the study of the dominating breakup channels involving $n \alpha^{6} \mathrm{He}$ or $3 \mathrm{n} 2 \alpha$ in the final state, with special emphasis dedicated in this contribution to the three-particle channel. One could also mention the known change of the decay rate for ${ }^{7} \mathrm{Be}$, which was measured most thoroughly. The change in the $K$-capture rate by $\sim 10^{-2}$ due to the influence of the energy of chemical bond and the atomic configuration of the environment (including measurements with ${ }^{7} \mathrm{Be}$ placed inside the fullerene $\mathrm{C}_{60}$ ) was registered (see Refs. [5-16]). It has been experimentally and theoretically found that the chemical environment (chemical bond, pressure etc.) effect resulted in changing $(\sim 0.1-1.0 \%)$ the corresponding decay constant. The helium-isotope massspectroscopy method for measuring the triton decay constant for various cases of the electron environment was used to determine the tritium half-life without allowance for decay to beta-electron bound states and to calculate the respective reduced half-life in Ref. [5-7]. More intriguing effects are considered in a case of $\alpha$-decay (see Refs. In [7]). Results on variation of the decay rate of Mössbauer isomers due to interference of electromagnetic waves in the system of the emitter and a screen from the same atom in the ground state situated at a distance of $2 \mathrm{~mm}$ seem quite impressive [19]. The values of the measured relative variation of the decay rate for ${ }^{119 \mathrm{~m}} \mathrm{Sn}$, ${ }^{125 \mathrm{~m}} \mathrm{Te}$ reach $\sim 10 \%$. The elementary cooperative electron- $\beta$ and $\gamma$-nuclear processes in atoms and molecules were considered in the pioneering papers by Migdal (1941), Levinger (1953), Schwartz (1953), Gol'danskyLetokhov-Ivanov (1971-1976), Kaplan-Markin-Yudin (1973-1975), reviews by Batkin-Smirnov (1980), papers by Freedman (1974), Carlson et al. (1968), Intemann (1983), Isozumi et al. (1977), Law- Campbell (1975), Martin-Cohen (1975), Mukouama et al. (1978), LawSuzuki (1982), Wauters-Vaeck (1997) et al [5-20]. The elementary cooperative electron $\alpha$-nuclear processes were considered in the papers by Levinger (1953), Hansen (1974), Watson (1975), Anholt-Amundsen (1982), Law (1977), Mukoyama-Ito (1988) et al (see Refs. [5-10]). In this context, the known Mössbauer, Szilard-Chalmers and other cooperative effects should be mentioned. The consistent quantum electrodynamics (QED) theory of cooperative electron $\gamma$-nuclear processes in atoms and molecules is developed in Refs. [7,24-31]. In fact, it is possibly a reverse bridging between nuclear structure theory and quantum chemistry (atomic and molecular physics). Data on $\beta$-decay parameters can be used for studying the chemical bond nature, treating the spatial structure of molecular orbitals, identifying the electron states in some tritiumcontaining systems and diagnostics of the compounds by means of exchange of the hydrogen atoms by tritium ("tritium probe").

\section{ELEMENTS OF MODERN $\beta$-DECAY THEORY AND COOPERATIVE ELECTRON- $\beta$-NUCLEAR PROC- ESSES}

As it is well known, the fundamental process behind $\beta$ decay is weak interaction of the down (up) quarks (for example: $\mathrm{d} \rightarrow \mathrm{u}+\mathrm{e}^{-}+\overline{\mathrm{v}}_{\mathrm{e}}$ etc) via the exchange of virtual bosons $\left[81.8\left(W^{ \pm}\right)\right.$and $\left.\left.91.2\left(Z^{0}\right) \mathrm{GeV} / \mathrm{c}^{2}\right)\right]$.

The first theory of $\beta$-decay was proposed by E. Fermi (1934), who introduced the local (contact) 4-fermion interaction of the nucleons and leptons. Hamiltonian of the Fermi nucleon-lepton interaction is as follows

$$
H_{\beta}=G_{\beta}\left(\bar{\Psi}_{p} \gamma_{\mu} \Psi_{n}\right)\left(\bar{\Psi}_{e} \gamma^{\mu} \Psi_{v}\right)
$$

Here $G_{\beta}$ is the Fermi constant, $\Psi$ are the fourcomponent wave functions of the particles (solutions of the Dirac equation), $\bar{\Psi}_{e}=\Psi^{+} \gamma_{0}, \gamma^{\mu}$ are the Dirac matrices, $\mu=0,1,2,3,4 ; \gamma^{0}=\gamma_{0} ; \gamma^{i}=-\gamma_{i}(i=1,2,3)$.

The nucleon-lepton interaction had purely vector form in the Fermi theory. The modern " $\mathrm{V}-\mathrm{A}$ " theory usually uses an effective $\beta$-decay Hamiltonian which was introduced by Feynman and Gell-Mann

$$
H_{\beta}=\frac{G_{\beta}}{\sqrt{2}} J^{\mu}(x) L_{\mu}(x)+\text { c.c. },
$$

where $J^{\mu}$ is the nucleonic current, $L_{\mu}$ is the leptonic current and $x$ is a spatial-temporal coordinate.

Despite a great progress in development of the comprehensive theory for the nuclear $\beta$-decay (electroweak interactions), hitherto many practical questions are far from a satisfactory treatment. The further consistent calculations of the $\beta$-decay parameters that take into account accompanying cooperative effects are needed. The widespread quantum mechanical methods (such as the HartreeFock (HF) method, the random-phase approximation, the Coulomb approximation (CA), the Hartree-Fock-Slater (HFS) and Dirac-Fock (DF) methods, DFT etc) are usually used in the atomic calculations and calculations of the $\beta$-allowed (superallowed) transitions parameters [5-7].

The difficulties of the corresponding calculations are well known (insufficiently correct account for exchange and correlation in the wave functions of $\beta$-particle, problem of gauge invariance, generation of the non-optimized bases of the wave functions for a discrete spectrum and continuum etc). The nuclear, relativistic, radiative corrections should be accurately taken into account too. As a rule, to estimate the $\beta$-spectrum shape and decay parameters, the special tables $[5,16]$ of the Fermi functions are usually used (the CA data). In some papers (see Refs. [5]) the HFS approach that takes into account the nuclear 
finite size effect was used. In some papers (see Refs. $[28,29]$ and references therein) the DF method is used. A gauge-invariant QED PT formalism for the calculation of the spectra and wave functions for heavy atoms while taking into account the relativistic, correlation, nuclear, and QED effects has been developed in Refs. [23-28]. This formalism provides two optimized gauge invariant (GI) calculation schemes with the DF (GIDF) and DKS (GIDKS) zeroth approximation. Below, the DKS scheme is used in our calculation.

As it is well known, a probability of the transition from the initial state $\mid \xi>$ with the energy $E_{\xi}$ to some final state $<f \mid$ with the energy $E_{f}$ per unit of time is defined as follows

$$
d W_{\xi, f}=\left.(2 \pi / \hbar)|<f| H|\xi>|^{2}(d N / d E)\right|_{E=E_{0}}, E_{0}=E_{f}-E_{\xi},
$$

where the value $(d N / d E)$ defines a density of the final states of a system per unit of energy and the corresponding matrix element is

$$
<f|H| \xi>=\int \psi_{f} H_{\beta} \psi_{\xi} d^{3} r_{1} \ldots d^{3} r_{A}
$$

where the interaction Hamiltonian $H_{\beta}$ and wave functions of the initial $\psi_{\xi}$ and final $\psi_{f}$ states. The expression for a number of the $\beta$-, $\tilde{v}$-particles with energy in the interval from $E$ till $E+d E$ is as follows

$$
\begin{gathered}
d W_{\xi f}=\frac{1}{2 \pi^{3} \hbar^{7} c^{5}}\left|\left\langle f\left|H_{\beta}\right| \xi\right\rangle\right|^{2} \sqrt{E_{e}^{2}-m^{2} c^{4}} E_{e}\left(E_{0}-E_{e}\right)^{2} d E_{e}, \\
d W_{\xi f}=\frac{1}{2 \pi^{3} \hbar^{7} c^{5}}\left|\left\langle f\left|H_{\beta}\right| \xi\right\rangle\right|^{2} \sqrt{\left(E_{0}-E_{\tilde{r}}\right)^{2}-m^{2} c^{4}}\left(E_{0}-E_{\tilde{v}}\right) E_{\tilde{v}}^{2} d E_{\tilde{r}} .
\end{gathered}
$$

Further we will study the allowed and super allowed $\beta$-transitions. The contribution of these transitions is the most significant to the resulting spectrum of the $\beta$-decay. At the same time, the forbidden transitions contribution is usually about a few percent of the total intensity. Distribution of $\beta$ particles on energy in a case of the allowed transitions is as follows

$$
d W_{\beta}(E) / d E=\frac{1}{2 \pi^{3}} G^{2} \cdot F(E, Z) \cdot E \cdot p \cdot\left(E_{0}-E\right)^{2} \cdot|M|^{2}
$$

Here $E, p=\left(E^{2}-1\right)^{1 / 2}$ are the total energy and pulse of $\beta$ particle; $E_{0}=1+\left(E_{b} / m_{e} c^{2}\right), E_{b}$ is the boundary energy of $\beta$ spectrum; $|M|$ is a matrix element, which is not dependent on an energy in a case of the allowed $\beta$-transitions. The Fermi and integral Fermi functions are defined as follows: [7]

$$
\begin{gathered}
F(E, Z)=\frac{1}{2 p^{2}}\left(g_{-1}^{2}+f_{+1}^{2}\right), \\
f\left(E_{0}, Z\right)=\int_{1}^{E_{0}} F(E, Z) \cdot E \cdot p \cdot\left(E_{0}-E\right)^{2} d E .
\end{gathered}
$$

Here $f_{+1}$ and $g_{-1}$ are the relativistic electron radial functions; the indexes $\pm l=\chi$, where $\chi=(l-j) /(2 j+1)$. The halflife period can be defined as follows

$$
T_{1 / 2}=2 \pi^{3} \ln 2 /\left[G_{\beta}^{2}|M|^{2} f\left(E_{0}, Z\right)\right]
$$

Here two calculation schemes can be used: i) The relativistic electron radial wave functions are calculated on the boundary of the spherical nucleus with radius $R$ (see $[13,14])$; ii) The values of these functions in zero are used in further computing. In the next paper we present the theoretical basis of our relativistic many-body perturbation theory with the optimized Dirac-Kohn-Sham zeroth approximation for the further studying and computing the $\beta$-decay parameters for a number of allowed (superallowed) transitions (for example, ${ }^{33} \mathrm{P}_{-}{ }^{33} \mathrm{~S},{ }^{241} \mathrm{Pu}^{241} \mathrm{Am}$ and others rock elements) and studying a chemical bond effect on $\beta$-decay parameters.

\section{REFERENCES}

1. Meyer V.A., Vaganov P.A. Fundamentals of nuclear geophysics. Moscow: Nedra, 1978.

2. Pshenichny G.A. Interaction of radiation with matter and modeling the problems of nuclear geophysics. Moscow: Nedra, 1982.

3. Yakubovich A.L., Zaytsev E.I., Przhiyaglovsky S.M. Nuclear geophysical methods of analysis of the mountains-governmental rocks. Moscow: Nedra, 1988.

4. Rusov V.D., Glushkov A.V., Vaschenko V.N. et al. Galactic cosmic rays - clouds effect and bifurcation model of the earth global climate. Part 1. Theory. Journal of Atmospheric and Solar-Terrestrial Physics (Elsevier Ltd.), 2010, vol.72, pp.498-508.

5. Gelepov B.C., Zyryanova L.N., Suslov Yu.P. Beta processes. Leningrad, 1972. $372 \mathrm{p}$.

6. Marciano W., White S. (Eds). Electromagnetic Probes of Fundamental Physics. Singapore: World Scient, 2003, 560 p.;

7. Glushkov A.V., Khetselius O.Yu., Lovett L. Electron-Nuclear Spectroscopy of Atoms and Molecules and Chemical Environment Effect on the beta-Decay parameters. Advances in the Theory of Atomic and Molecular Systems Dynamics, Spectroscopy, Clusters, and Nanostructures. Series: Progress in Theoretical Chemistry and Physics. Berlin: SPRINGER, 2009, vol.20, pp. 125-152. (Eds: Piecuch P., Maruani J., Delgado-Barrio G., Wilson S.)

8. Kaplan I. Endpoint energy in the molecular beta spectrum, atomic mass defect and the negative $\mathrm{m}^{2}{ }_{\mathrm{v}}$ puzzle. J.Phys.G.: Nucl.Part.Phys., 1997, vol.23, pp.683-692.

9. Glushkov A.V. Laser- electron-beta-nuclear spectroscopy of atomic and molecular systems and chemical environment effect on the betadecay parameters: Review. Photoelectronics, 2010, no.19, pp. 2842.

10. Wauters L., Vaeck N. Study of the electron rearrangement induced by nuclear transmutation: A B-spline approach applied to the beta decay of ${ }^{6}$ He. Phys. Rev. C., 1996, vol.53, no. 1, pp. 497-500.

11. Wauters L., Vaeck N., Godefroid N., var der Hart H., Demeur M. Recoil-induced electron excitation and ionization in one- and twoelectron ions. J. Phys. B.;Atom. Mol.Opt. Phys., 1997, vol.30, 
pp.4569-4588.

12. Drukarev E.G., Strikman M.I. Final state interactions of beta electrons and related phenomena. JETP, 1986, vol.64(10), pp.11601168.

13. Gedasimov V.N., Zelenkov A.G., Kulakov V.M., Pchelin V.A., Sokolovskaya M.V., Soldatov A.A., Chistyakov L.V. An effect of chemical environment on spectra of conversion electrons for E3transitions of ${ }^{99 \mathrm{~m}}$ Tc. JETP. (8694), pp.1169-1178 (1984); Soldatov A.A. Preprint of I.V.Kurchatov Institute for Atomic Energy IAE-3916 (1983).

14. Tegen R. Beta decay of the free neutron and a (near) degenerate neutrino mass. Nucl.Phys.A., 2002, vol.706, pp. 193-202.

15. Izosimov I.N., Kazimov A.A., Kalinnikov V.G., Solnyshkin A.A., Suhonen J. Beta-Decay Strength Measurement, Total Beta-Decay Energy Determination and Decay-Scheme Completeness Testing by Total Absorption gamma-ray Spectroscopy. Phys. Atom. Nucl., 2004, vol. 67, no. 10, pp. 1876-1882.

16. Karpeshin F.F., Trzhaskovskaya M.B., Gangrskii Yu.P. Resonance Internal Conversion in Hydrogen-Like Ions. JETP, 2004, vol.99, no. 2, pp. 286-289.

17. Kopytin I.V., Karelin K.N., Nekipelov A.A. Exact Inclusion of the Coulomb Field in the Photobeta Decay of a Nucleus and Problem of Bypassed Elements. Phys. Atom. Nucl., 2004, vol. 67, no. 8, pp. 1429-1441.

18. Litvinov Yu.A., Attallah F., Beckert K., et al. Observation of a dramatic hindrance of the nuclear decay of isomeric states for fully ionized atoms. Phys. Lett. , 2003, B 573, 80

19. Baldwin G.G., Salem J.C., Goldansky V.I. Approaches to the development of gamma ray lasers. Rev.Mod.Phys., 1981, vol.53, no.4, pp. 687-742.

20. Glushkov A.V. Relativistic and Correlation Effects in Spectra of Atomic Systems. Moscow-Odessa: Nauka, 2006.

21. The Fundamentals of Electron Density, Density Matrix and Density Functional Theory in Atoms, Molecules and the Solid State. Progress in Theoretical Chemistry and Physics. Berlin: Springer, 2004, vol. 14 (Eds: N. Gidopoulos, S. Wilson).

22. Supercomputing, Collision Processes, and Applications, Physics of Atoms and Molecules. New York: Kluwer, 1999 (Eds: K. Bell, K.A. Berrington, D.S.F. Crothers, A. Hibbert, K. Taylor).

23. Glushkov A.V. Advanced Relativistic Energy Approach to Radiative Decay Processes in Multielectron Atoms and Multicharged Ions. Quantum Systems in Chemistry and Physics: Progress in Methods and Applications. Series: Frontiers in Theoretical Physics and Chemistry. Berlin: SPRINGER, 2013, vol.26, pp. 231-254 (Eds: K. Nishikawa, J. Maruani, E. Brandas, G. Delgado-Barrio, P. Piecuch).
24. Khetselius O.Yu. Relativistic energy approach to cooperative electron-gamma-nuclear processes: NEET Effect. Quantum Systems in Chemistry and Physics: Progress in Methods and Applications. Series: Progress in Theoretical Chemistry and Physics. Berlin: SPRINGER, 2013, vol.26, pp. 217-230 (Eds: K. Nishikawa, J. Maruani, E. Brandas, G. Delgado-Barrio, P. Piecuch).

25. Glushkov A.V., Khetselius O.Yu., Svinarenko A.A. Relativistic theory of cooperative muon-gamma-nuclear processes: Negative muon capture and metastable nucleus discharge. Advances in the Theory of Quantum Systems in Chemistry and Physics. Series: Frontiers in Theoretical Physics and Chemistry. Berlin: SPRINGER, 2011, vol.22, pp. 51-70 (Eds: P. Hoggan, E. Brandas, G. Delgado-Barrio, P. Piecuch).

26. Glushkov A.V. Operator Perturbation Theory for Atomic Systems in a Strong DC Electric Field. Advances in Quantum Methods and Applications in Chemistry, Physics, and Biology. Series: Frontiers in Theoretical Physics and Chemistry. Berlin: SPRINGER, 2013, vol.27, part 2, chap.9, pp. 161-178 (Eds: M. Hotokka, J. Maruani, E. Brändas, G. Delgado-Barrio)

27. Glushkov A.V., Dubrovskaya Yu.V., Gurnitskaya E.P., Khetselius O.Yu. Consistent quantum theory of the recoil induced excitation and ionization in atoms during capture of electron and neutron. Journ. of Phys. CS, 2006, vol.35, pp. 425-430.

28. Glushkov A.V., Khetselius O.Yu., Dubrovskaya Yu.V., Vitavetskaya L.A. Quantum calculation of cooperative muon-nuclear processes: discharge of metastable nuclei during $\mu$ capture. Recent Advances in Theory of Phys. and Chem. Systems. Springer, 2006, vol.15, pp.301-308.

29. Dubrovskaya Yu.V., Khetselius O.Yu., Turin A.V. The beta electron final state interaction effect on beta decay probabilities for ${ }^{42} \mathrm{Se}$ nucleus within relativistic Hartree-Fock approach. Photoelectronics, 2007, no. 16, pp.120-122.

30. Glushkov A.V., Lovett L., Khetselius O.Yu., Gurnitskaya E.P., Dubrovskaya Yu.V., Loboda A.V. Generalized multiconfiguration model of decay of multipole giant resonances applied to analysis of reaction $(\mu-\mathrm{n})$ on the nucleus ${ }^{40} \mathrm{Ca}$. International Journal of Modern Physics A. Particles and Fields; Gravitation; Cosmology; Nuclear Physics, 2009, vol. 24, no.2-3, pp.611-615.

31. Stepanenko S.N., Shnaindman V.A. An account of baroclinity in model of a boundary layer. Sbornik LPI. Leningrad, 1984, pp.5963.

32. Glushkov A.V., Serga E.N. Renorm-group approach to studying a turbelence spectrum in general dynamics of atmosphere. Bulletin of OSENU, 2011, no. 11, pp. 143-148.

\title{
ОБЗОР ФУНДАМЕНТАЛЬНЫХ ЯДЕРНО-ГЕОФИЗИЧЕСКИХ ИССЛЕДОВАНИЙ В ОГЭКУ: ЭЛЕМЕНТЫ СТАНДАРТНОЙ ТЕОРИИ БЕТА РАСПАДА И НОВОЙ КООПЕРАТИВНОЙ ЭЛЕКТРОН-ВЕТА-ЯДЕРНОЙ СПЕКТРОСКОПИИ
}

\author{
О.В. Глушков, д-р ф.-м. н., проф.
}

\author{
Одесский государственный экологический университет \\ ул. Львовская,15 ,65016, Одесса, Украина,glushkovav@gmail.com
}

Статья открывает серию публикаций, посвященных обзору новых результатов оригинальных ядерного геофизических исследований, выполненных на кафедре математики ОГЭКУ и его лабораторий (вычислительной и квантовой математики и механики, ядерной геофизики и др.). Первоначальный материал преимущественно концентрируется на фундаментальных проблемах, решение которых составляют теоретическую основу дальнейших прикладных ядерной-геофизических исследований. 
Кратко изложены элементы современной теории процессов бета-распада и качественно обсуждаются характерные особенности так называемых кооперативных электрон-бета-ядерных процессов в атомах и молекулах, в том числе возбуждения, ионизации, электронной перестройкой, вызванной ядерных реакций и бета-распада.. Несколько факторов учитываются: изменение пределов интегрирования в функции Ферми и интегральной функции Ферми, энергетические поправки для различных химических элементов (веществ), а также возможности связанного бета-распада или других экзотических каналов распада.

Ключевые слова: ядерная геофизика, процессы бета-распада, кооперативная электрон-бетаядерная спектроскопия.

\title{
ОГЛЯД ФУНДАМЕНТАЛЬНИХ ЯДЕРНО-ГЕОФІЗИЧНИХ ДОСЛІДЖЕНЬ В ОДЕКУ: ЕЛЕМЕНТИ СТАНДАРТНОЇ ТЕОРІЇ БЕТА РАСПАДА І НОВОЇ КООПЕРАТИВНОЇ ЕЛЕКТРОН-ВЕТА-ЯДЕРНОЇ СПЕКТРОСКОПІї
}

О.В. Глушков, д-р ф.-м. н., проф.

\author{
Одеський державний екологічний університет, \\ вул. Львівська, 15, 65016 Одеса, Украӥна, glushkovav@gmail.com
}

Стаття відкриває серію публікацій, присвячених огляду нових результатів оригінальних ядерного геофізичних досліджень, виконаних на кафедрі математики ОДЕКУ і його лабораторій (обчислювальної та квантової математики і механіки, ядерної геофізики та ін.). Початковий матеріал переважно концентрується на фундаментальних проблемах, вирішення яких складають теоретичну основу подальших прикладних ядерної-геофізичних досліджень. Коротко викладені елементи сучасної теорії процесів бета-розпаду і якісно обговорюються характерні особливості так званих кооперативних електрон-бета-ядерних процесів в атомах і молекулах, у тому числі збудження, іонізації, електронною перебудовою, викликаної ядерних реакцій і бета-розпаду. Декілька факторів враховуються : зміна меж інтегрування у функції Фермі та інтегральній функції Фермі, енергетичні поправки для різних хімічних елементів (речовин), а також можливості пов'язаного бета-розпаду або інших екзотичних каналів розпаду.

Ключові слова: ядерна геофізика, процеси бета-розпаду, кооперативна електрон-бета-ядерна спектроскопія. 